\title{
APLIKASI METODE MAGNETOTELURIK DALAM INTERPRETASI STRUKTUR PANAS BUMI: DAERAH PANAS BUMI GUNUNG KARUA, TANA TORAJA SULAWESISELATAN
}

\author{
Ahmad Zarkasyi ${ }^{1}$, Firman Syaifuddin ${ }^{2}$, Nugroho Syarif Setiawan ${ }^{2}$ \\ ${ }^{1}$ Pusat Sumber Daya Geologi \\ 2 Departemen Teknik Geofisika, Fakultas Teknik Sipil Lingkungan dan Kebumian, \\ Institut Teknologi Sepuluh Nopember (ITS) \\ e-mail : firman@geofisika.its.ac.id
}

\begin{abstract}
Abstrak. Wilayah panas bumi Bittuang memiliki manifestasi yang terdiri dari mata air panas dan batuan alterasi dengan suhu reservoir diperkirakan sekitar $200^{\circ} \mathrm{C}$. Hasil penelitian sebelumnya dan pengamatan lapangan mengarahkan kami untuk melakukan penelitian berkelanjutan di daerah ini, yang bertujuan untuk menentukan struktur resistivitas hingga kedalaman sekitar 2-4 km. Dalam penelitian ini kami menggunakan inversi dua dimensi (2D) magnetotelurik (MT), yang digunakan untuk mencirikan struktur resistivitas listrik reservoir panas bumi. Untuk mencapai tujuan penelitian ini, kami melakukan pengukuran medan magnetotelurik (MT). Hasil penelitian menunjukkan adanya kemenerusan yang ditunjukkan dari data geologi dan zona resistivitas rendah pada permukaan dangkal dengan kedalaman sekitar 1-1,25 km yang paling mungkin terkait dengan batuan alterasi atau clay cap. Zona di bawah clay cap dengan resistivitas lebih tinggi (50-250 ohm.m) diindikasikan sebagai zona reservoir.
\end{abstract}

Kata Kunci: magnetotelurik; panasbumi; inversi 2D; Bittuang

\begin{abstract}
Bittuang Geothermal area has manifestations consisting of hot springs and alterations rock with reservoir temperature estimated about $200^{\circ} \mathrm{C}$. The result of previous research and field observations lead us to carry out continuing research in this area, which is aimed to determine resistivity structure to a depth about 2-4 km. In this paper we utilized two-dimensional (2D) magnetotelluric (MT) inversions, which used to characterize the electrical resistivity structure of geothermal reservoirs. We carried out Magnetotelluric (MT) field measurements to achive the purpose of this study. The results reveal the existence of a strike which indicated from the geological data and a low resistivity zone at a shallow surface with depth about 1-1,25 km that is most probably associated with alteration rock or clay cap. The zone below the claycap with higher resistivity (50-250 ohm.m) is indicated as reservoir zone.
\end{abstract}

Keywords: magnetotelluric; geothermal, 2D inversion, Bittuang

\section{PENDAHULUAN}

Daerah panas bumi Gunung Karua terletak di Kabupaten Tana Toraja, Provinsi Sulawesi Selatan (Gambar 1). Indikasi potensi panas bumi Bittuang berupa dua kelompok manifestasi panas bumi yaitu di daerah Balla dan Cepeng dengan temperatur air panas (AP) dengan sekitar $37-96,7^{\circ} \mathrm{C}$, batuan ubahan dan solfatara. Penelitian maupun eksplorasi geosain untuk mendapatkan data potensi energi panas Gunung Karua di Tana Toraja dimulai oleh Pusat Sumber Daya Geologi-Badan Geologi di tahun 2009 dengan metode geologi, geokimia, dan geofisika (geolistrik, gaya berat dan magnetik). Hasil penelitian merekomendasikan zona prospek panas bumi yang harus dilanjutkan dengan metode geofisika dengan penetrasi lebih dalam.
Akuisisi data magnetotelurik (MT) telah dilaksanakan pada tahun 2012 dan 2014. Jumlah titik MT pada tahun pertama sebanyak 38 titik dengan sebaran berada pada bagian selatan. Pengukuran pertama ini melingkupi manifestasi panas bumi air panas (AP) Cepeng sampai dengan AP Balla. Akuisisi data MT dilanjutkan pada tahun 2014 sebanyak 25 titik dengan area sebaran dilanjutkan ke arah utara atau sampai dengan tubuh Gunung Karua. Hasil penelitian dengan metode MT diharapkan dapat memberikan informasi mengenai struktur sistem panas bumi Gunung Karua secara lebih detail dan jelas.

Metode Magnetotelurik (MT) memiliki sejarah panjang dalam eksplorasi panas bumi. Respons MT dari reservoir suhu tinggi menunjukkan resistivitas 
sebagai indikator tidak langsung dari fluida panas bumi, sebagai respons terhadap batuan teralterasi (Pellerin dkk., 1996). Resistivitas merupakan besaran fisis primer bumi yang sangat dipengaruhi oleh proses aktivitas hidrotermal di reservoir panas bumi. Jika dipetakan, resistivitas dapat digunakan untuk menyimpulkan zona rekahan dengan permeabilitas tinggi yang belum dimanfaatkan dan terisi oleh fluida panas (Gasperikova dkk., 2015).

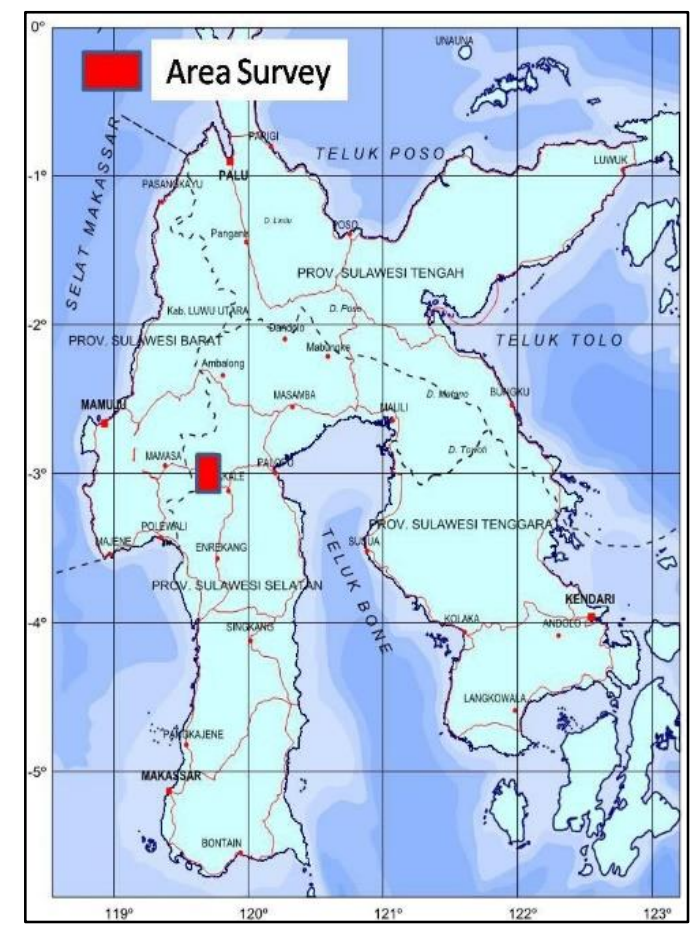

Gambar 1 Daerah panas bumi Gunung Karua-Tana Toraja, Sulawesi Selatan

\section{Daerah Panas Bumi Gunung Karua}

Daerah panas bumi Gunung Karua disebut juga daerah panas bumi Bittuang. Geomorfologi area ini didominasi oleh morfologi perbukitan non-vulkanik, puncak Gunung Karua, tubuh Gunung Karua, dan kaki Gunung Karua.

Batuan yang menyusun daerah ini berupa batuan batuan malihan, sedimen, batuan terobosan dan batuan produk-produk vulkanik (Gambar 2). Batuan vulkanik lava Gunung Karua-3 merupakan vulkanik termuda $(0,3 \pm 0,1$ juta tahun) yang diperkirakan berperan penting dalam pembentukan sistem panas bumi Bittuang (Anonim a, 2009; Soetoyo, 2010).
Struktur yang berkembang terdiri dari struktur rim kaldera, sekumpulan sesar normal berarah baratlaut-tenggara, baratdaya-timurlaut, dan berarah hampir utara-selatan. Bagian sesar yang berarah hampir utara-selatan inilah yang diduga mengontrol keberadaan manifetasi panas bumi berupa mata air panas (AP) Balla dan Cepeng. Terdapat pula struktur berupa sesar mendatar yang berarah baratdaya-timurlaut yang memotong dan menimbulkan pergeseran pada struktur dan batuan yang sudah terbentuk sebelumnya.

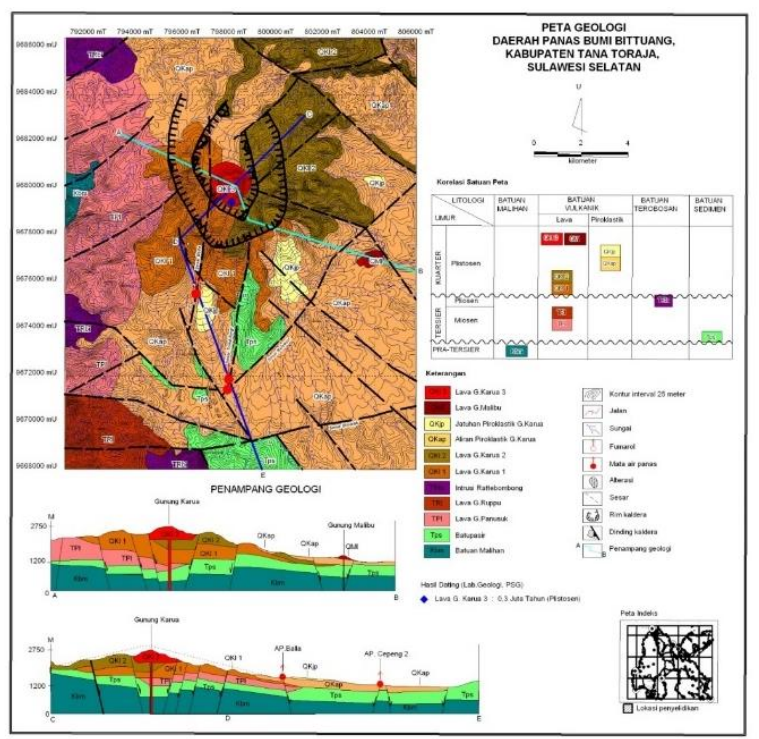

Gambar 2 Geologi daerah panas bumi Gunung Karua/Bittuang (Anonim a, 2009 dan Soetoyo, 2010)

Terdapat dua tipe dari AP yang muncul di Bittuang (Anonim a, 2009; D Kusnadi dan D Setiawan, 2009). Mata air panas Balla bertipe klorida sedangkan Cepeng masuk tipe air bikarbonat. Mata air panas Balla berada di zona partial equilibrium, yang merupakan indikator adanya proses water rock interaction antara batuan dan fluida panas. Proses ini menyebabkan terbentuknya air panas bertemperatur tinggi $\left(90-96^{\circ} \mathrm{C}\right)$ dengan temperatur reservoir diperkirakan sebesar $200^{\circ} \mathrm{C}$ (Gambar 3).

\section{METODOLOGI}

Metode MT merupakan salah satu metode geofisika yang dapat menggambarkan sifat elektrik (distribusi tahanan jenis) bawah permukaan yang memanfaatkan variasi medan elektromagnetik alami 
sebagai sumbernya. Rentang frekuensi dari medan elektromagnet alami berkisar antara $10-4 \mathrm{~Hz}$ hingga $104 \mathrm{~Hz}$ (Chave dan Jones, 2012)

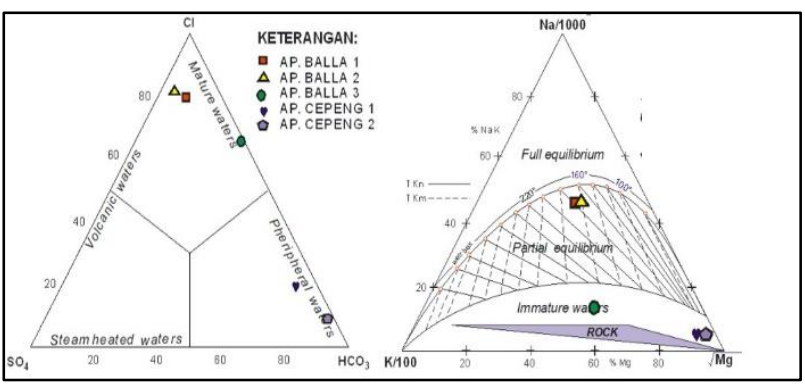

Gambar 3 Geokimia daerah panas bumi Gunung Karua/Bittuang (Anonim a, 2009 dan Kusnadi, 2010)

Frekuensi tinggi, lebih dari $1 \mathrm{~Hz}$, dihasilkan dari aktivitas petir, sedangkan untuk frekuensi rendah, kurang dari $1 \mathrm{~Hz}$ dihasilkan dari interaksi solar wind dan medan magnet bumi. Fluktuasi medan magnet menyebabkan arus listrik sedangkan variasi konduktivitas listrik berarah lateral dan vertikal di kerak bumi disebabkan oleh adanya ion atau benda konduktif padat (Zhdanov, 2002).

Tahanan jenis atau resistivitas diperoleh dari perbandingan nilai medan listrik dan medan magnet yang disebut juga sebagai persamaan Cagniard (Cagniard, 1953). Persamaan ini merupakan hasil dari persamaan Maxwell dengan asumsi gelombang bidang:

$$
\rho_{a}=\frac{1}{5} f x\left|\frac{E}{H}\right|^{2}
$$

dimana :

$$
\begin{array}{ll}
\rho_{a} & : \text { tahanan jenis semu (ohm.m) } \\
\mathrm{f} & : \text { frekuensi (Hz) } \\
\mathrm{E} & : \text { medan listrik }(\mathrm{mV} / \mathrm{km}) \\
\mathrm{H} & : \text { medan magnet }(\mathrm{nT})
\end{array}
$$

Kedalaman efektif dalam metode MT bergantung kepada tahanan jenis batuan dan frekuensi yang digunakan. Penetrasi kedalaman efektif didapatkan dengan menggunakan persamaan (Zhdanov, 2009):

$$
\delta=\frac{1}{\alpha}=\sqrt{\frac{2}{\mu_{0} \sigma \omega}}
$$

dimana :

$$
\begin{array}{ll}
\delta & : \text { skin depth }(\mathrm{m}) \\
\omega & : \text { frekuensi sudut } \\
\sigma & : \text { konduktivitas }(\mathrm{S} / \mathrm{m})
\end{array}
$$

$\mu_{0} \quad$ : permeabilitas magnetik $(\mathrm{H} / \mathrm{m})$

Data MT yang diperoleh dan dilanjutkan dalam proses memiliki rentang frekuensi $300 \mathrm{~Hz}$ sampai dengan 0,01 Hz. di Gunung Karua. Total stasiun berjumlah 63 titik (Gambar 4). Kualitas data mayoritas berkualitas baik kecuali beberapa titik muncul bump pada frekuensi rendah $<0.1 \mathrm{~Hz}$. Kelemahan data MT di daerah ini adalah efek statik yaitu pergeseran vertikal ke atas dan ke bawah terhadap nilai yang sebenarnya yang disebabkan oleh heterogenitas lokal di permukaan dan juga faktor topografi.

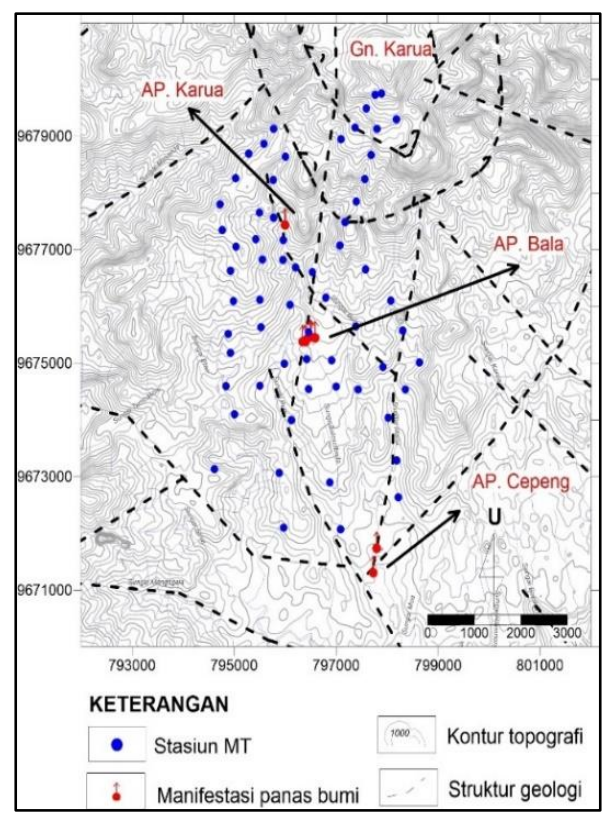

Gambar 4 Stasiun pengukuran MT

Analisis arah strike untuk pemilihan arah rotasi menggunakan metode kualitatif. Hasil analisis ini ditentukan arah 00 atau tidak dirotasi. Alasan ini karena pertimbangan analisa kualitatif (sesar geologi) yang cendrung berarah utara-selatan. Koreksi statik menggunakan metode statistik. Metode ini menentukan median nilai tahanan jenis semu dari titik-titik MT yang berada di sekitar titik MT yang akan dikoreksi (Gambar 5).

Pemodelan data MT di daerah Gunung Karua menggunakan teknik inversi 2D. Inversi 2D merupakan salah satu proses pengolahan data yang melibatkan teknik penyelesaian matematis dan statistik dalam menentukan distribusi sifat fisis batuan bawah permukaan (M.R.Annas Qahhar dkk., 2015). Metode yang digunakan adalah NLCG (NonLinear Conjugate Gradient) yang dapat secara 


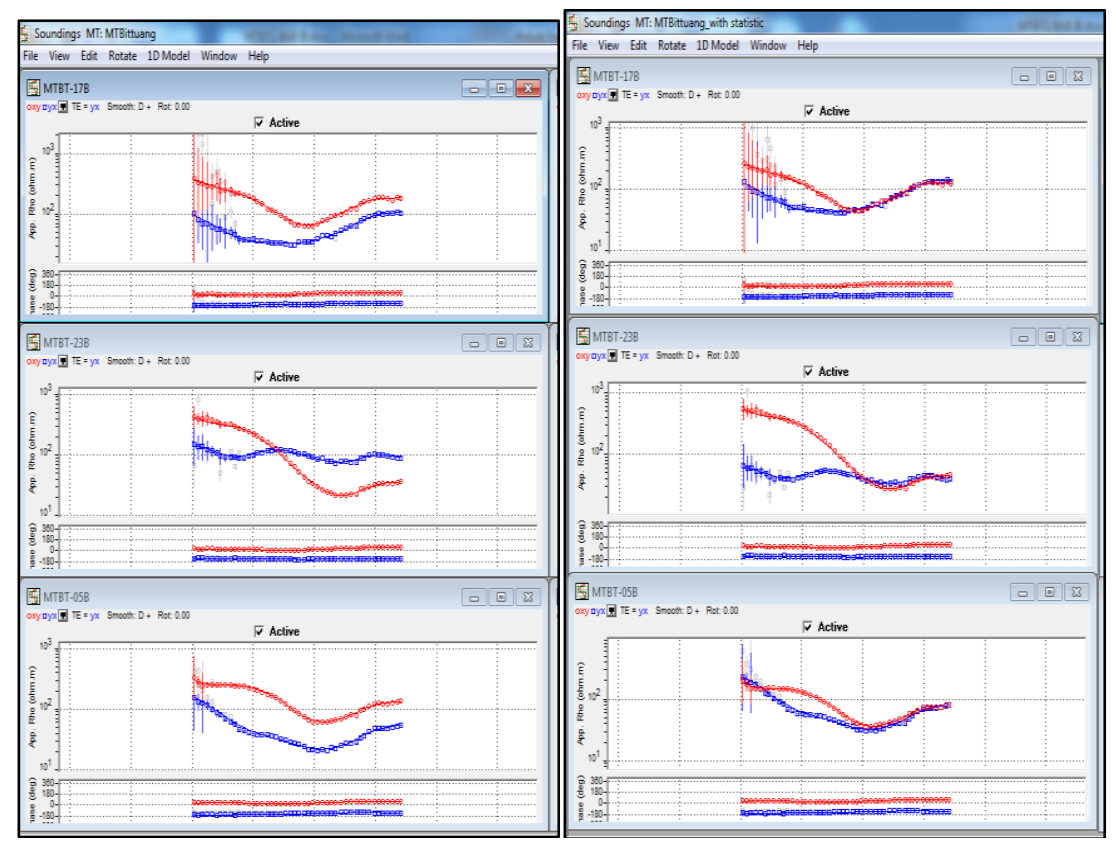

Gambar 5 Contoh data MT daerah Gunung Karua sebelum (kiri) dan sesudah (kanan) dilakukan koreksi statik

langsung meminimalisasi problem yang bukan kuadratik, membebaskan kerangka iterasi dan inversi linear (Rodi dan L. Mackie, 2001). Metode ini mengevaluasi fungsi forward untuk setiap model terbaru. Oleh karena itu, setiap satu kali iterasi pada inversi untuk setiap lintasan menyelesaikan dua atau tiga problem forward (Siripunvaraporn, 2012).

\section{HASIL DAN PEMBAHASAN}

Tahanan jenis semu invarian yang dicuplik pada frekuensi 100, 10, 1 dan 0,1 Hz (Gambar 6). Pada frekuensi $100 \mathrm{~Hz}$ terdapat tahanan jenis semu $<50$ ohm.m yang muncul di daerah sekitar AP Balla dan menerus ke arah Gunung Karua sampai dengan mata air panas di lembah/kaki selatan Gunung Karua. Tahanan jenis < 50 ohm.m ini meluas area penyebarannya pada frekuensi $10 \mathrm{~Hz}$ tetapi semakin terisolir dan mengecil areanya pada frekuensi $1 \mathrm{~Hz}$ bahkan tidak terdeteksi lagi pada frekuensi rendah $(0,1 \mathrm{~Hz})$.

Nilai tahanan jenis $<50$ ohm.m ini diperkirakan memiliki asosiasi dengan batuan lava dan aliran piroklastik produk Gunung Karua yang mengalami proses alterasi hidrotermal. Batuan teralterasi semakin luas penyebarannya pada frekuensi $10 \mathrm{~Hz}$ dan mulai berkurang intesitas alterasinya pada frekuensi $1 \mathrm{~Hz}$.

Di luar area bertahanan jenis lebih $<50$ ohm.m, terpetakan tahanan jenis $70-200$ ohm.m. Nilai tahanan jenis jenis tinggi ini konsisten tersebar bahkan dengan nilai yang semakin tinggi di atas $\mathbf{5 0 0}$ ohm.m pada frekuensi rendah. Tahanan jenis tinggi ini di bagian tengah ke selatan diperkirakan respon batuan yang lebih kompak dan diperkirakan sebagai batuan basement.

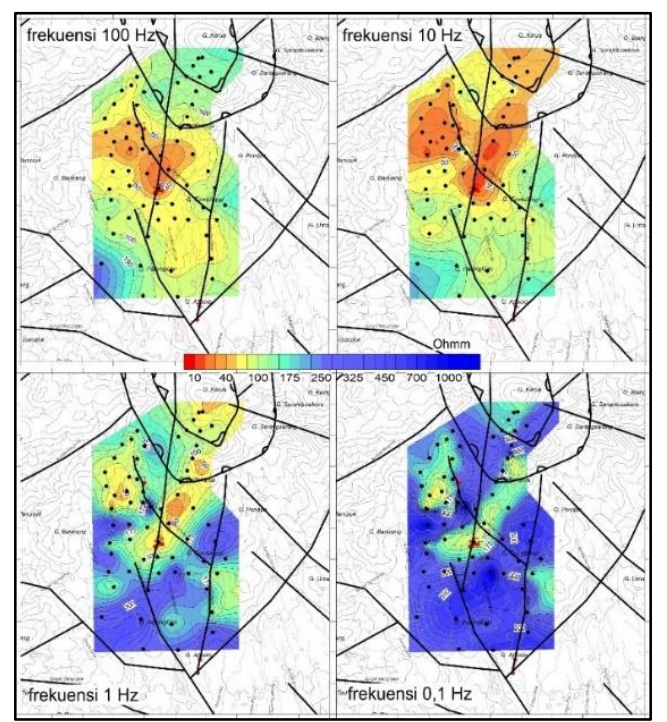

Gambar 6 Tahanan jenis semu invariant yang dicuplik pada frekuensi 100,10,1, dan $0.1 \mathrm{~Hz}$

\section{Model Tahanan Jenis}

Model tahanan jenis yang dihasilkan dari inversi 2D dipotong pada berbagai kedalaman. Kompilasi hasil perpotongan ditampilkan pada Gambar 7. 


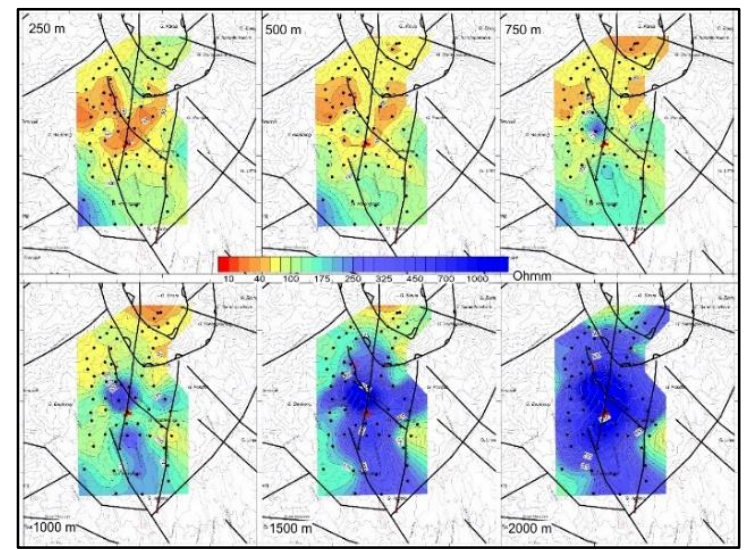

Gambar 7 Model tahanan jenis 2D yang dicuplik pada kedalaman 250, 500, 750, 1000, 1500, dan 2000 meter.

Pada kedalaman 250-500 meter sebaran batuan bertahanan jenis $<50$ ohm.m berada di sekitar mata air panas Balla menerus ke arah Gunung Karua yang diperkirakan merupakan batuan produk vulkanik yang teralterasi/terubahkan sehingga nilai tahanan jenisnya menjadi rendah. Luas sebaran tahanan jenis $<50$ ohm.m ini mulai mengecil pada kedalaman 7501000 meter dan tergantikan oleh nilai tahanan jenis sekitar 50-100 ohm.m. Di atas kedalaman 1000 meter, sebaran tahanan jenis di lokasi-lokasi mata air panas semakin tinggi nilainya. Diperkirakan pada kedalaman 100-1500 meter ini merupakan zona transisi dari tahanan jenis rendah ke tahanan jenis tinggi ini. Zona transisi ini diduga sebagai zona batas antara lapisan penudung (batuan teralterasi) dengan lapisan reservoir pada sistem panas bumi Bittuang. Pada kedalaman 2000 meter sebaran tahanan jenis didominasi oleh tahanan jenis tinggi, diperkirakan pada kedalaman ini sudah merupakan batuan dasar.

Nilai tahanan jenis < 50 ohm.m yang diinterpretasikan sebagai respon dari batuan teralterasi tersebar di wilayah sekitar AP Balla yang penyebarannya ke arah utara atau puncak Gunung Karua dan menutup di sekitar kaki selatannya.

Tahanan jenis rendah ini terdeteksi di model penampang (Gambar 8) mulai dari permukaan hingga elevasi 500-600 m dpl atau kedalaman sekitar 1000-1250 meter. Reservoir panas bumi diperkirakan terletak di bawah lapisan claycap tersebut dengan nilai tahanan jenis antara 50-250 ohm.m dan tersebar di sekitar AP Balla hingga bagian utara ke arah Gunung Karua. Bagian puncak dari reservoir tersebut diperkirakan berada di bagian tengah dengan ketebalan reservoir sekitar 1000 meter.

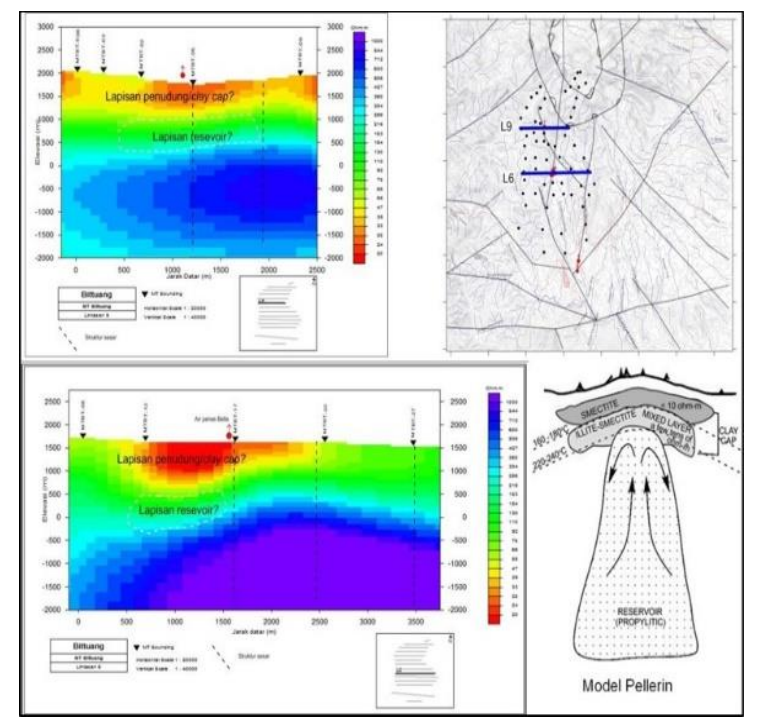

Gambar 8 Interpretasi penampang model tahanan jenis 2D dikorelasikan dengan sistem panas bumi

\section{PENUTUP}

\section{Simpulan dan Saran}

Hasil pemodelan 2D data MT dapat digunakan untuk mendefinisikan sistem panas bumi Gunung karua/Bittuang seperti lapisan penudung dan reservoir. Lapisan penudung/caprock diinterpretasikan pada lapisan batuan bertahanan jenis $<50$ ohm.m yang berasal dari batuan vulkanik teralterasi. Lapisan ini terdeteksi dekat permukaan hingga kedalaman sekitar 1000-1250 meter. Reservoir panas bumi diperkirakan berada mulai kedalaman 1000-1250 meter dengan nilai tahanan jenis antara 50-250 ohm.m dan ketebalan sekitar 1000 meter.

\section{Ucapan Terima Kasih}

Ucapan terima kasih tim penulis hantarkan kepada para staf Pusat Sumber Daya Geologi bidang panas bumi yang telah berperan serta dalam penulisan ini. Kegiatan diskusi terutama tentang informasi geologi daerah sangat bermanfaat dalam interpretasi hasil MT. 


\section{DAFTAR PUSTAKA}

Anonim a (2009), Laporan Survei Geofisika Terpadu Daerah Panas Bumi Bittuang, Kabupaten Tana Toraja, Sulawesi Selatan. Pusat Sumber Daya Geologi, Badan Geologi, Bandung, Diambil dari http://psdg.bgl.esdm.go.id/perpus/index.php?p =show_detail\&id=127.

Anonim b (2009), Laporan Survei Terpadu Geologi dan Geokimia Daerah Panas Bumi Bittuang, Kabupaten Tana Toraja, Provinsi Sulawesi Selatan Pusat Sumber Daya Geologi, Badan Geologi, Bandung,.

Anonim c (2012), Laporan Survei MT daerah Panas Bumi Bittuang, Kabupaten Tana Toraja, Provinsi Sulawesi Selatan Pusat Sumber Daya Geologi, Badan Geologi, Bandung,.

Cagniard, L. (1953), "Basic Theory of the Magneto-Telluric Method of Geophysical Prospecting", Geophysics, Vol.18. http://doi.org/10.1190/1.1437915.

Chave, A.D. dan Jones, A.G. (2012), The Magnetotelluric Method: Theory and Practice, Cambridge University Press. http://doi.org/10.1017/CBO9781139020138.

D Kusnadi dan D Setiawan (2009), "Penyelidikan Geokimia Daerah Panas bumi Bittuang, Kabupaten Tanan Toraja, Sulawesi Selatan", Prosiding Pemaparan Hasil - Hasil Kegiatan Lapangan dan Non Lapangan Tahun 2009 Pusat Sumber Daya Geologi, Badan Geologi, Bandung, .

Gasperikova, E., Rosenkjaer, G., Arnason, K., A. Newman, G. dan Lindsey, N. (2015), "Resistivity characterization of the Krafla and Hengill geothermal fields through 3D MT inverse modeling", Geothermics, Vol.57. http://doi.org/10.1016/j.geothermics.2015.06.0 15.

M.R.Annas Qahhar, Yunus Daud, Surya Aji Pratama, Ahmad Zarkasyi, Asep Sugianto dan Edi Suhanto (2015), Modeling of Geothermal Reservoir in Lawu field Using 2-D Inversion of Magnetotelluric Data,

Pellerin, L., Johnston, J.M. dan Hohmann, G.W. (1996), "A numerical evaluation of electromagnetic methods in geothermal exploration",
GEOPHYSICS, Vol.61, No.1, hal. 121-130. http://doi.org/10.1190/1.1443931.

Rodi, W. dan L. Mackie, R. (2001), "Nonlinear Conjugate Gradients Algorithm For 2-D Magnetotelluric Inversion", Geophysics, Vol.66, hal. 174-187. http://doi.org/10.1190/1.1444893.

Siripunvaraporn, W. (2012), "Three-Dimensional Magnetotelluric Inversion: An Introductory Guide for Developers and Users", Surveys in Geophysics, Vol.33, No.1, hal. 5-27. http://doi.org/10.1007/s10712-011-9122-6.

Soetoyo (2010), "Penyelidikan Geologi Daerah Panas bumi Bittuang, Kabupaten Tanan Toraja, Sulawesi Selatan", Prosiding Pemaparan Hasil Hasil Kegiatan Lapangan dan Non Lapangan Tahun 2009 Pusat Sumber Daya Geologi, .

Zhdanov, M.S. (2002), Google-Books-ID: tHtDETV7VCoC, Geophysical Inverse Theory and Regularization Problems, Elsevier.

Zhdanov, M.S. (2009), Google-Books-ID: 5UpLWIzX9HIC, Geophysical Electromagnetic Theory and Methods, Elsevier. 